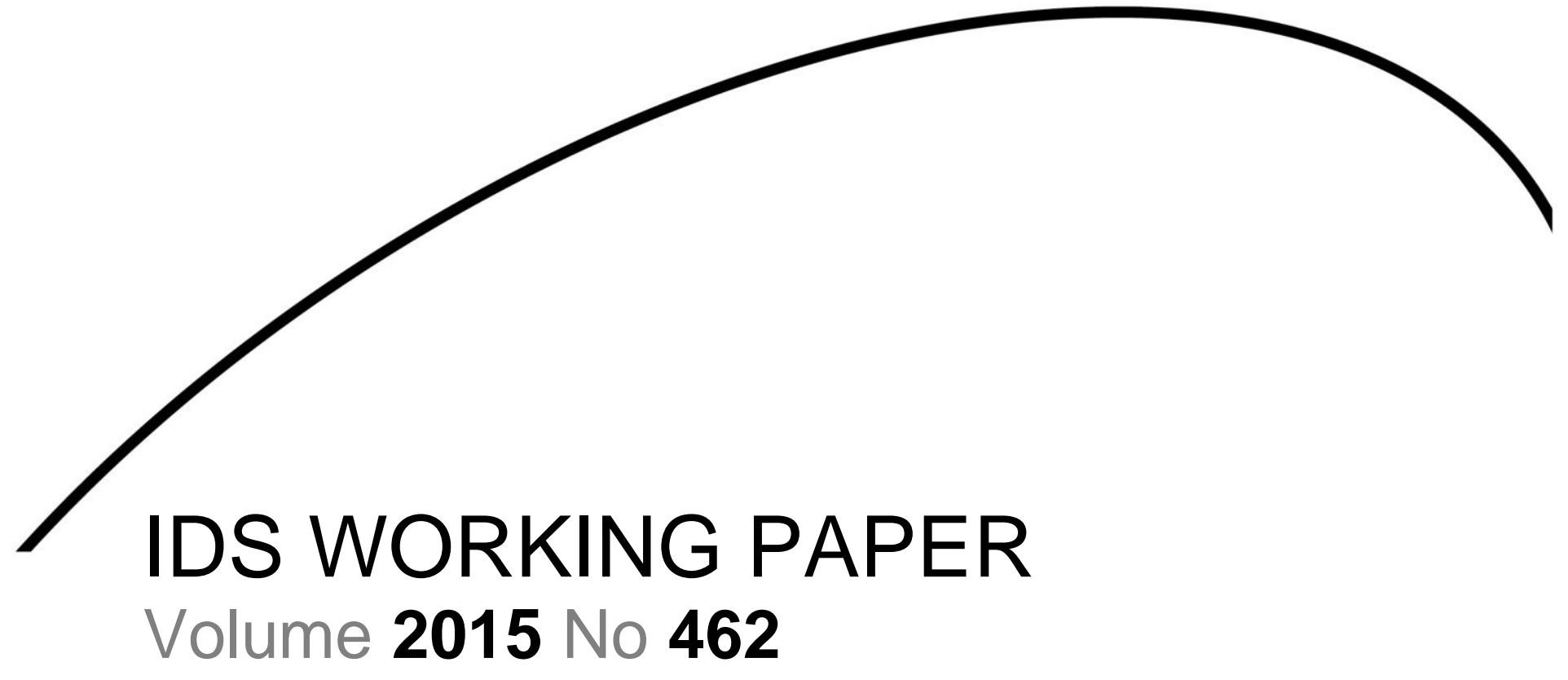

Towards a Global Reporting System for Development Cooperation on the SDGs: Promoting Transformational Potential and Impact

Jiajun Xu and Richard Carey

September 2015 
Research on sustainable development financing supported by the DFID Research Project 'China International Development Research Network (CIRDN)' has contributed to the preparation of this Working Paper. The CIDRN is hosted by the Research Centre for International Development (RCID) at the China Agricultural University in Beijing, where it was founded in 2013.

Disclaimer: The results reported represent the views of the authors and not necessarily those of DFID.

Towards a Global Reporting System for Development Cooperation on the SDGs: Promoting Transformational Potential and Impact Jiajun $\mathrm{Xu}$ and Richard Carey

IDS Working Paper 462

(C) Institute of Development Studies 2015

ISSN: 2040-0209 ISBN: 978-1-78118-270-3

A catalogue record for this publication is available from the British Library.

All rights reserved. Reproduction, copy, transmission, or translation of any part of this publication may be made only under the following conditions:

- with the prior permission of the publisher; or

- with a licence from the Copyright Licensing Agency Ltd., 90 Tottenham Court Road, London W1P 9HE, UK,

or from another national licensing agency; or

- under the terms set out below.

This publication is copyright, but may be reproduced by any method without fee for teaching or nonprofit purposes, but not for resale. Formal permission is required for all such uses, but normally will be granted immediately. For copying in any other circumstances, or for re-use in other publications, or for translation or adaptation, prior written permission must be obtained from the publisher and a fee may be payable.

Available from:

Communications and Engagement Unit, Institute of Development Studies, Brighton BN1 9RE, UK

Tel: +44 (0) 1273915637

E-mail: bookshop@ids.ac.uk

Web: www.ids.ac.uk/publications

IDS is a charitable company limited by guarantee and registered in England (No. 877338) 


\title{
Towards a Global Reporting System for Development Cooperation on the SDGs: Promoting Transformational Potential and Impact
}

\author{
Jiajun Xu and Richard Carey
}

Summary: The proposed SDGs constitute a comprehensive, universal and interactive agenda of structural transformations as the pathway to sustainable development, leaving noone behind while creating green economies. This new global development agenda demands a reporting system which both engages a much wider range of development co-operation actors than the traditional Development Co-operation Directorate (DCD-DAC) donors and reflects the radically changing structure and complexion of the global economy and development finance. Existing development cooperation reporting systems are not geared to supporting the programme design, implementation, coordination and review processes implicit in the SDGs. We propose a reporting system based around transformational potential and impact (TPI) statements in upstream programme and project reporting linked to the SDGs and involving all suppliers and forms of externally provided development cooperation, including market finance leveraged by sovereign creditworthiness. Our proposal provides a framework for thinking and acting at the level of transformation and facilitates the mapping of external cooperation to national and regional programmes of structural transformation. The TPI statements could thus constitute a commitment and review system analogous to the Intended Nationally Determined Contributions (INDCs) methodology being developed as the basis for a new global climate change regime to be agreed at the Paris Conference in December 2015.

Keywords: reporting systems; sustainable development financing; post-2015 agreements

Jiajun Xu is Assistant Professor, Centre for New Structural Economics, National School of Development, Peking University. She worked as a research specialist responsible for research on development finance at the United Nations' High Level Panel Secretariat on the Post-2015 Development Agenda and as an international consultant on debt sustainability in the World Bank's Concessional Finance and Global Partnerships Vice-Presidency (now the Development Finance Vice-Presidency).

Richard H. Carey is former Director of the Organisation for Economic Co-operation and Development's (OECD) Development Co-operation Directorate (DAC-DCD) and a founding co-Chair of the China-DAC Study Group. He is member of the Advisory Council on Rising Powers in Development at the Institute of Development Studies (IDS) at Sussex University and Chairs the International Advisory Committee of the China International Development Research Network (CIDRN). 


\section{Contents}

Summary, keywords and author notes 3

Introduction: reporting on transformational actions in a multi-actor development community

1 From the MDGs to the SDGs: implications of the transformation paradigm for international reporting systems

2 A Transformation Potential and Impact (TPI) reporting system for the SDGs 10

3 Conclusion $\quad 12$

References 


\section{Introduction: reporting on transformational actions in a multi-actor development community}

At the upcoming UN Summit meeting in late September 2015, Heads of State are to agree On a set of Sustainable Development Goals (SDGs) to replace the Millennium Development Goals. The proposed text entitled 'Transforming our World: The 2030 Agenda for Global Action' (UN, 2015b) will incorporate, as an annex, the 'Addis Ababa Action Agenda', the outcome document of the recent $3^{\text {rd }}$ UN Financing for Development (FFD3) (UN 2015a). And in December 2015, Heads of State will meet in Paris to forge a new global climate change agreement to replace the Kyoto Protocol in 2020. (United Nations Framework Convention on Climate Change).

Four features of these foundational international accords for global objectives stand out. First, they are universal, based on the common but differentiated responsibilities principle that is making it possible to overcome previous North-South stalemates and to engage all UN member countries in the policy commitments and actions. Second, they recognise and welcome the input and participation of a much wider development community: bilateral actors from both North and South, multilateral organisations and development banks, civil society, private sectors, philanthropists, and scientists and professional associations. Third, following the lines of the High Level Panel of Eminent Persons on the Post-2015 Development Agenda which cast its recommendations in the form of 'five transformative shifts' (High Level Panel 2013), their agendas are explicitly cast as transformational and integrated, rather than incremental and discrete. Fourth, they bring global trends and economic, social, and environmental dynamics inside the development paradigm. This generates policy coordination and coherence issues throughout the SDGs, salient features that were either implicit or external in the highly compact set of reduced form proxies for development progress that constitute the Millennium Development Goals (MDGs).

Thus, the compelling challenge ahead is how to record and assess the potential and impact of transformational actions across a wide frontier in a multi-actor development community. While current debates mainly focus on what kinds of 'indicators' should be selected to specify goal and target achievement, little has been done to explore how an upstream reporting system can be constructed so as to incentivize, and indeed make possible, the transformation/systemic/integrated mode of the SDGs. To promote discussion how to fill this gap, our paper tackles the question of how a reporting system that focuses on transformational objectives, efforts and impacts might be constructed. The key concept is that development cooperation efforts should be designed, reported and monitored in terms of their intended transformational potential and impact in relation to the agreed SDGs as reflected in national and regional development strategies and collective efforts to supply global public goods. The transformational potential and impact (TPI) concept is already in effect the foundation for the current progress towards the post-Kyoto framework, where the 'Intended Nationally Determined Contributions (INDCs)' have become the basis for commitments that will be submitted ahead of the Paris conference, consolidated there, and then become subject to subsequent rounds of peer review when actual impacts can be assessed over time. What we propose is essentially an adaptation of that concept into an upstream reporting system for all contributors to the SDGs, followed up with real-time evaluation and peer review processes that track and evaluate downstream transformational impacts in a medium and long-term time frame. The upstream segment of this reporting system concerns a different set of issues from the extensive data generation and indicator 
tracking work mandated in the Transforming Our World document, although driving towards outcomes that should eventually show up in the indicator system.

While transformational aspirations are at the heart of the SDGs, no reporting system so far is up to the task of reporting on transformational actions in a multi-actor development community. Current reporting systems for Official Development Assistance (ODA), for export credits and for debt sustainability constrain rather than encourage the vision, action and innovation needed to generate transformative development (Xu and Carey, 2015). The SDG outcome text, 'Transforming our World: The 2030 Agenda for Global Action', spells out an elaborate set of arrangements in the UN system for monitoring and reporting. These arrangements involve a massive effort to collect more data in developing countries, including via new information technologies, on downstream progress and outcomes. As of now there is no proposed system, such as the INDCs, for reporting and reviewing current actions in terms of their intended impacts. Yet upstream policy and programming design and coordination and agency incentive issues are vital in determining the effectiveness of national strategies and international cooperation efforts.

Our proposed TPI reporting system differs from established reporting systems on aid efforts such as the Development Assistance Committee (DAC) systems and the International Aid Transparency Initiative (IATI) in two key respects: first, it would use the SDGs as the framework for reporting, whose political legitimacy would help the TPI reporting system to engage a much broader range of stakeholders; and second, it would revolve around a common, compact reporting format with a single set of questions designed to create incentives for programme providers to think and act in terms of transformational potential and impact, with systemic outcomes in specific contexts as a central concern for all. It would work to correct persisting problems of perverse agency incentives in the development cooperation industry and to promote the changes in development management methodologies needed to support transformational development processes in the context of other interventions and multiple external factors (Ferrero and Zepeda 2014).

Without such a TPI reporting system in place to orient development programming, the problems and perverse incentives in the development cooperation industry could undermine the whole endeavour to generate transformative change at the national, regional and global levels. The critical current weaknesses may be identified as follows:

First, in the fragmented cooperation system, no one is responsible or incentivised to assess whether collective development efforts actually produce systemic capacities as outcomes. The multiplication of international actors, driven by their own incentive systems generates a large incoherent aid sector, swamping the small capacities of local actors. Although the successive development effectiveness forums have addressed this problem, country and region level partnerships that empower local actors and institutions on a sustained and sustainable basis and generate transformation dynamics remain elusive (Ferrero and Zepeda 2014). Social impact concepts and instruments begin to address systemic issues, in both developed and developing countries (Social Impact Investment Task Force) and systemic evaluation is an emerging field, but so far there is a lack of information system designs that can link micro and macro impacts (OECD 2015).

Second, time horizons for actors are too short and scale too low to effect transformational change and make risk-taking viable. While the catalytic role of aid in underwriting innovation and risk-taking is increasingly recognised, there is currently no way of capturing the transformational intent and impact of such uses of aid. And studies show that incentives and time frames and human resources in both bilateral and multilateral aid agencies have hindered the emergence of mindsets and mandates to engage in scaling up projects, with only a few aid agencies having ventured into this area (Chandy et al. 2012). The imperative to demonstrate visible development outcomes within a short timeframe in response to 
taxpayers' demand for accountability drives much aid agency behaviour. Monitoring and evaluation are still only rarely in the systemic and real-time modes needed to deal with complexity and to enhance innovation, limiting their utility to key actors (IDS 2014, 2015a; Michael Quinn Patton, 2011). Meanwhile, the prevailing short-termism in capital markets and corporations means that long-term financing supply from vast pools of savings and accumulated profits falls short of required investment (Haldane 2015; Kay 2012; OECD 2013).

Third, the legitimacy of existing reporting systems is increasingly contested. The evolution of the emerging countries as significant providers of development finance has generated fundamental problems for traditional aid reporting systems. While North-South aid is carefully tracked at the individual transactions level, involving a complex set of classifications and a governance system in the form of the DAC Working Party on Aid Statistics (recently renamed the Working Party on Development Finance), China and other significant emerging capitalproviders are not part of this reporting system. For South-South development cooperation there is no such classificatory or quantitative tracking system because financial transfers have been incidental to its essence as knowledge transfer among poor countries. South South cooperation has, since the Bandung Conference in 1955, embraced the principle of mutual benefit in contrast to the 'one-way' welfare transfer from rich donors to poor recipients, a core principle of the ODA concept (Xu and Carey 2014). The Addis Ababa Action Agenda provides for open discussion on the modernisation of the ODA measurement and on the proposed measure of 'total official support for sustainable development' (UN 2015a para 55), but it is unclear at this point whether and how these discussions might relate to reporting and monitoring of the SDGs.

Last but not least, coherence across policy approaches and policy communities becomes more necessary and more difficult. For example, the segregation between development finance and climate finance is a stumbling block to achieving a universal development agenda. Although the DAC tracks climate change financing via 'Rio markers,' in the UNFCCC negotiations climate change financing has emerged as a specific political objective with its own targets and capacity building, funding and knowledge sharing institutions (Briner; Brown; Clapp; Caruso 2014). The climate change policy communities and the development policy communities are largely distinct, with sporadic rather than systemic interaction, creating challenges for integration of finance streams in national budget processes (Miller 2012). UN negotiators in these two fields are also distinct with distinct terminologies and concepts. The transformational post-2015 agenda envisages the SDGs as an integrated package, working together so as to exploit many synergies between different goals. Yet it is tempting for donors and governments to react to the large number of goals by picking off their favourites, replicating the silo pathology of the MDGs. Equally it is challenging for governments and UN agencies to work across the sectors and silos that they habitually occupy.

To address the above pathologies, there is a need and an opportunity in the upcoming UN Summit in September 2015 for Heads of State to call for a TPI reporting system, drawing on the analogy with the INDCs. 


\section{From the MDGs to the SDGs: implications of the transformation paradigm for international reporting systems}

The current state of play in the global development negotiations of 2015 has yielded significant progress in the international development cooperation domain:

- $\quad$ First, the Financing for Development and SDG Outcome documents constitute a decisive move towards thinking of development in terms of dynamic transformative processes supported by integrated financing frameworks.

- Second, the comprehensive nature of the goals and targets, taken together with the likely adoption of Intended Nationally Determined Contributions (INDCs) as the foundation for the Climate Change regime to be agreed in December in Paris, facilitates forward-looking reporting of development cooperation programmes.

- $\quad$ Third, the SDGs provide a universal and agreed framework, so that reporting systems and vocabularies can be a shared public good for global governance.

What are implications of the post-2015 transformation paradigm for international reporting systems?

The opening chapter of Transforming Our World provides a vision and context for a comprehensive and universal agenda which is explicitly transformational in character with a special focus on reducing inequality. That is, the goals and targets seek to decisively change the human condition across a wide front in all countries, under the overarching domains of people, planet, prosperity and peace and via partnerships in all targeted areas. A major underlying transformation embedded in the goals and targets is the transformation of low productivity/income rural-based societies into productive and sustainable urban-based societies with sustainable agriculture and well-functioning cities, with effective and sustainable systems providing energy, food, education and vocational training, transport, health, social protection, human rights and flourishing cultures and ecologies for all. These outcomes are to be underpinned by active, effective and accountable states with progressively improving capacities, revenues and rule of law; by facilitating the emergence of productive enterprises and well-functioning markets; and by harnessing science, technology and innovation. At the international level this involves well-functioning trade, financial and fiscal systems and a new mechanism for promoting science, technology and innovation. Connecting growth and development pathways with planetary capacities and 'leaving no one behind' are two overarching objectives. ${ }^{1}$

This consensus works, politically and functionally, because of the comprehensiveness of the agenda. It resolves some longstanding stalemates, integrates the current dynamics changing the shape of the global economy, welcomes the new development finance institutions reflecting new global dynamics (notably the role of China), and requires explicit strategies and action plans from all sides.

This big picture provided upfront, together with the action agenda and the review systems embodied in the SDG Summit outcome document thus constitute a major addition to the

The transformation concept is already largely reflected in vision statements and action strategies in many developing countries, including in Africa. (African Centre for Economic Transformation 2014; African Development Bank 2015; African Union 2015). 
evolving global governance system. We come back to this point further below. We note here however that the SDGs involve new reporting and assessment system challenges and opportunities in the following three areas:

Country-level: the Addis Ababa Action Plan calls for 'Cohesive nationally owned sustainable development strategies, supported by integrated national financing frameworks'. The SDG strategies and the national financing frameworks will together provide more dynamic scenarios for national, regional and global level cooperation as human capital development, physical infrastructure, urbanisation and agricultural development are seen in a much more interactive mode. Innovation in technologies, finance and business models are already rapidly changing the pace and nature of the development process (Sheng 2013). This makes a forward-looking and upfront reporting system for external development cooperation programming linked to national SDG strategies all the more necessary for programme formulation and for monitoring/evaluation.

Global-level: as noted above, the range of dynamic transformation vectors now in play at the global level has been captured in the opening section of the SDG outcome document. They include dramatic differences in demographic trends, the role of mega cities nationally and globally, digitalisation with its impact on business and employment models, climate change and disaster frequencies and magnitudes, and shifts in economic and political balances/geographies presenting new challenges and opportunities for international cooperation. These transformative vectors can and must be recognised and harnessed, and related cooperation encapsulated in the reporting systems for the SDGs.

Public Entrepreneurship and Private Entrepreneurship: the recognition of the importance of active capable states as facilitators of transformation is a major advance in the Third International Conference on Financing for Development (FFD3) and SDG outcome documents. Private entrepreneurship as a key source of vision, action and innovation is also a key theme in these documents. Public entrepreneurship and private entrepreneurship together 'co-create' economic development in a dynamic, interactive process, generating new economic landscapes with new technological paradigms (Boix 2015; Brewer 2008; Klein et al, 2010; Mazzucato, 2013; Xu and Carey, 2013). Public entrepreneurship has three essential features: (a) vision, (b) action in the presence of uncertainty, and (c) readiness to innovate and foster learning by doing and innovation in their societies at large (Xu and Carey, 2015). This role for the state goes beyond establishing an enabling environment for sustainable development. It means actively organising the large public investments and services needed for any market economy to function, and incubating economic activities to the point where local, regional and global enterprises move to invest in the future. The emergence of growing middle classes with spending power and new, inclusive mobile-based financial systems will be a major stimulus to private entrepreneurship and inclusive growth, not least in Africa (Ncube and Lufumpa 2014). Nevertheless, the under-provision of basic collective goods, institutions and infrastructures in most developing countries indicates a huge underestimation in the past of the public roles and investments needed to generate and support a market based economy (Kaplan 2013; Page 2012) The experience of the successful emerging economies serves to illustrate this key point. Development cooperation programming that supports the role and capacities of the state as a proactive organiser of scaled up public investment and public goods, drawing in private entrepreneurs with management and technological knowledge and equity finance to exploit the opportunities thus opened up, sets off a dynamic development and financing process. This applies equally to finding a way forward towards viable political settlements in fragile states (Kaplan 2008; Ghani and Lockhart 2010; OECD 2014). Reporting systems should be designed to incentivise and capture such scaling up ambitions and processes.

Against this background, as the transition from the MDGs to the SDGs proceeds in the period ahead, the key concept of transformative intent, action and impact needs to be very 
consciously factored into the design of reporting systems at the national, regional and global levels. We now set out the key ingredients in the Transformation Potential and Impact reporting system in more detail.

\section{A Transformation Potential and Impact (TPI) reporting system for the SDGs}

At the heart of our proposal is the key concept - 'Transformational Potential and Impact' (TPI). Rather than focusing on raising a larger volume of certain financial flows, TPI is dedicated to impacting deeply on the incentives for designing, assessing and evaluating sustainable development policies, programmes and projects across the whole multistakeholder system, based on the shared central vision of transformation. Financial support mechanisms and packages for development then emerge at the level of activities geared to goals and targets at country or region level in the context of the integrated financial frameworks called for in the Addis Ababa Action Agenda. The TPI reporting system is designed to foster synergies between goals in order to achieve the cross-cutting principle of 'leaving no one behind'. Meanwhile, the TPI reporting system recognises that at the more specific level of country contexts and implementation there will inevitably be tensions and trade-offs, for instance, the prospect that middle class driven entrepreneurial growth could be at the expense of the poorest and most marginalised. The TPI reporting system helps to confront these trade-offs and dilemmas rather than simply assuming them away.

Our proposal draws from two converging streams of work: the 'big dream-small wins' approach to climate change governance (Urpelainen 2013), and the new conceptual framework of 'public entrepreneurship' (Klein et al. 2010; Xu and Carey 2013), with its three elements: providing a shared long-term vision; creating innovative learning by doing societies; and acting on a decisive scale in the presence of uncertainty and risk.

Concretely, the TPI reporting system would consist of a concise questionnaire calibrated in terms of the SDGs and their targets. A single set of questions would apply to all development cooperation programming by a development cooperation provider, completed online and with strict word limits. The questionnaires and responses should be a strategic management instrument for high level policy makers, guiding programme design and implementation and strengthening internal and external coordination and coherence.

The key incentives embodied in the reporting questionnaire would be:

- Contributing to systemic capacities and scaling up

- Thinking and acting in longer term time frames

- Integrating externalities and spillovers, both functionally and regionally

- Thinking and acting across the SDGs where linkages and opportunities are manifest

- Operating on a learning by doing development process basis, with real-time monitoring and evaluation built into programme design

- Contributing to the cross-cutting principle of 'leaving no one behind'

- A rough sample of the questionnaire is as follows:

- What is the intended contribution of this programme to the SDGs (impact) in this specific context and over what time period?

- How does this activity contribute to the structural economic evolution and human development of the country/region?

- How does this activity help shape local/national/regional public management systems and capacities? 
- How does this activity link up with local SDG strategies and with other local and international actors?

- How will monitoring and evaluation processes be integrated into programme design and systemic capacity development?

- What spill-overs does this activity generate, positive or negative, for other goals and targets?

- What financial and technical assistance resources are provided?

- How does this programme/project contribute to the progress towards the goals from the perspective of inclusive development??

(Note: Financial resources would cover official finance, concessional and non-concessional; sovereign-backed financing such as export credits and state bank loans; grants from Foundations and Civil Society Organizations, and development impact bonds and green financing).

These questionnaires would be submitted on a voluntary basis to the UN Secretariat structures responsible for the SDG process. They would be publically available online. Search engine tools would be devised to enable synthetic narratives and reporting to be produced and links to national SDG strategies and information systems to be established. Incentives to participate would be essentially political and reputational and standards of reporting could be expected to improve over time for the same reason, as the transparency and review processes evolve (the INDC system in the climate change context provides a parallel). The TPI reporting system will move beyond the institutional domain and therefore connect to ground level and participatory assessment mechanisms. Transparency and participation are key to avoiding the pitfall that the reporting process becomes an elaborate tick box exercise which officials become very good at gaming. Reputational factors and the nature of the questions above should work to make such gaming rare.

Compared to other international reporting systems, the TPI system would have the following qualities:

- Calibrated on the SDG goals and targets. Capacity to investigate crossovers between different SDG goals and targets via the search engine technology.

- Comprehensive - all providers of development cooperation could participate and all financial assistance would qualify, in line with the Financing for Development outcome concept of integrated financing frameworks at the national level to support SDG strategies. It would include climate change finance under Goal 13.

- Focus on articulating long term systemic impacts, with corresponding influence on agency management levels and organisational cultures/behaviour. (Again analogous with the intended nationally decided contributions concept being introduced in the climate change negotiations).

- Concise yet rich in key forward looking information (the questionnaires could reference further documents and contact points). Financial information could be fed into the national integrated financial frameworks and assist with debt sustainability analysis (IMF 2014).

- Aggregations of reports and constructions of narratives, (using also the kind of search engine technology envisaged for the online platform proposed in paragraphs 123 of the Addis Ababa Action Agenda for the UN work on science, technology and innovation) would feed SDG review processes in the UN and elsewhere, including any roles that the G20 and other international institutions may undertake to support the SDG process.

The advantage of the system for countries with decentralised development cooperation/multiple agencies is that the reporting is composed at the programme management level but within overall strategic guidelines agreed at a high political level. 
Indeed, such reporting, with its standard, concise form would facilitate internal coordination at the strategic level in both single agency and multi-agency development cooperation systems. Of particular importance is the prospect that emerging country providers of development cooperation would join this reporting system. Joining such a system would be a high level political decision. In the case of China, we have argued elsewhere (Xu and Carey, 2014, IDS $2015 \mathrm{~b}$,) that China now has a major interest in the functioning of the international financing system. Interacting with others is now a strong element of Chinese international development finance policy (as witnessed in policy statements by China's leaders in the context of cooperation with Africa and in the Silk Road initiatives). Hence the transparency of its development finance becomes both more necessary functionally and feasible politically. Perhaps the G20 meeting to be hosted by China in 2016 could provide an occasion for making such a decision.

\section{Conclusion}

A world that works collectively in the transformation mode of the SDGs requires the modernization of global reporting systems to serve as an incentive-shaper in the changing landscape of sustainable development finance.

We propose a 'Transformational Potential and Impact' reporting approach to help to achieve six key incentive changes: contributing to systemic capacities and scaling up, thinking and acting in longer term time frames, thinking and acting across the SDGs and integrating externalities and spill-overs, both functionally and regionally, and operating on a learning by doing basis with real time evaluation, and contributing to the cross-cutting principle of 'leaving no one behind'.

This is a step towards generating the political and business incentives need to drive local and international development dynamics towards inclusive and resilient sustainable development. In this vision, action, innovation cycles, reputational motivations and public and private entrepreneurship generate strong reinforcing actions in virtuous circles of technological and business model change. Such virtuous circles can change the psychology and prospects of low-income and fragile countries and regions, with integrated national financing frameworks, to achieve their economic and social transformation. The TPI reporting system will need to allow for qualitative narratives about potential impact, as well as quantitative estimations. As clarified at the beginning, this paper is not aimed at selecting indicators to specify targets and goals. Yet many of the principles outlined here - around qualitative as well as quantitative criteria, leaving no one behind, integration across goals, indicators of systemic change etc will be relevant to the development of indicators too.

As seen above, the Intended Nationally Determined Commitments concept (INDC) introduced in the climate change negotiating framework is analogous to the TPI concept. In other contexts similar approaches are also emerging. The G20 agreement in Brisbane to aim collectively to raise growth trajectories by 2 per cent, accompanied by over 1000 specific policy actions from individual members is indeed in the 'big dream-small wins' mode. So is the foundation of the $\mathrm{g} 7+$ association of fragile states, whose 20 members are seeking transition from fragility using country-specific and consolidated indicators and joint learning/mutual advice to reach this objective $(g 7+)$.

Our proposal comes with a caveat. Such a global reporting system would not generate financial data of the kind need to track international commitments, if those internationallyagreed commitments remain central political reference points (such as the $0.7 \%$ ODA target). It would thus not eliminate the need for the DAC Reporting system. It would rather provide 
the basis for a truly global reporting of development efforts at local and regional levels, in the SDG framework.

In summary, the 'Transformation Potential and Impact' approach could thus serve as the basis for a global reporting system legitimised by the SDGs and used by the wide and heterogeneous range of actors involved. For the first time ever, DAC countries and SouthSouth partners would participate in a shared global reporting system, without the need for laborious technical and political negotiations. It could and should be integrated with the Green Climate Fund information system (Green Climate Fund; Cheikhrouhou 2014). And it could and should contribute to country level information systems. Most importantly, it can help to drive the key incentive changes necessary to the realisation of a transforming post2015 agenda. 


\section{References}

African Center for Economic Transformation (2014) Growth with Depth, 2014 African Transformation Report. Ghana

African Development Bank (2013) At the Center of Africa's Transformation: Strategy for 2013-2022

African Union (2015) Agenda 2063

Boix, C. (2015) Political Order and Inequality: Their Foundations and Their Consequences for Human Welfare, New York: Cambridge University Press

Brewer, T.L. (2008) 'Climate Change Technology Transfer: A New Paradigm and Policy Agenda', Climate Policy 8.5: 516-26. doi:10.3763/cpol.2007.0451

Briner, G.; Kato, T.; Konrad, S. and Hood, C. (2014) Taking Stock of the UNFCCC Process and Its Inter-Linkages, Climate Change Expert Group Paper 2014(4), https://search.oecd.org/environment/cc/ (2014\%20)4\%20Inter-linkages\%20paper\%20revFinal.pdf

Brown, J.; Bird, N. and Schalatek, L. (2010) 'Climate Finance Additionality: Emerging Definitions and Their Implications', ODI Climate Finance Policy Brief 2: 1-11

Capacity Development for Development Effectiveness Facility (CDDE) (2015) Aid Information Management Systems, Accessed at www.aideffectiveness.org/aims on 18.8.2015

Caruso, R. and Jachnik, R. (2014) Exploring Potential Data Sources for Estimating Private Climate Finance, OECD Environment Working Papers 69, www.oecdilibrary.org/content/workingpaper/5jz15qwz4hs1-en

Chandy, L.; Hosono, A.; Kharas, H.J. and Linn, J.F. (eds) (2012) Getting to Scale: How to Bring Development Solutions to Millions of Poor People, Brookings Institution Press, https://books.google.co.uk/books?hl=en\&lr=\&id=sl27hPUYJhoC\&oi=fnd\&pg=PP1\&dq= getting+to+scale+homi\&ots=eq2aLvPk3u\&sig=O5fBay1CO6CIP9GZYHBs2o09RIA

Cheikhrouhou, H. (2014) Towards an Articulated Vision for Climate Finance: How Can It Support Ongoing Efforts to Scale-up Funding and Investments?, statement given by Executive Director of the Green Climate Fund on the occasion of the High-level Ministerial Dialogue on Climate Finance Held at the 20th Conference of the Parties of the UN Framework Convention on Climate. http://news.gcfund.org/wpcontent/uploads/2014/12/speech_EXD_2014_12_09_lima_cop20.pdf

Clapp, C.; Ellis, J.; Benn, J. and Corfee-Morlot, J. (2012) Tracking Climate Finance: What and How?, Paris: OECD, www.oecd.org/environment/cc/50293494.pdf.

DAC (2014a) Climate-Related Aid, OECD DAC Statistics, www.oecd.org/dac/environmentdevelopment/Climate-related\%20aid\%20Flyer\%20\%20March\%202014\% 20v3\%20final.pdf

DAC (2014b) DAC High Level Meeting Communiqué, 15-16 December 2014, Paris, www.oecd.org/dac/OECD\%20DAC\%20HLM\%20Communique.pdf 
Ferrero, G. and Zepeda, C. (2014) 'Rethinking Development Management Methodology: Towards a "Process Freedoms Approach"', Journal of Human Development and Capabilities, 15.1: 28-46, http;//dx.doi.org/10.1080/19452829.2013.877425

g7+ (2013) Note on the Fragility Spectrum, www.g7plus.org accessed 21/09/2015

G20 (2014a) G20 Leaders' Communiqué, Brisbane Summit, 15-16 November 2014, https://g20.org/wpcontent/uploads/2014/12/brisbane_g20_leaders_summit_ communique.pdf

G20 (2014b) G20 Leaders' Communiqué, Brisbane, 16 November 2014, www.g20.utoronto.ca/2014/2014-1116-communique.html

Ghani, A. and Lockhart, C. (2008) Fixing Failed States: A Framework for Rebuilding a Fractured World, New York: Oxford University Press

Green Climate Fund (2011) Governing Instrument for the Green Climate Fund, http://gcfund.net/fileadmin/00_customer/documents/pdf/GCFgoverning_instrument120521-block-LY.pdf Accessed 21/09/2015

Haldane, A. (2015) 'Who Owns a Company?', speech given at the University of Edinburgh Corporate Finance Conference on 22 May 2015, www.bankofengland.co.uk/publications/Pages/speeches/2015/833.aspxt on 18.8.2015

High Level Panel on the Post-2015 Development Agenda (2013) A New Global Partnership: Eradicate Poverty and Transform Economies through Sustainable Development, High Level Panel, www.post2015hlp.org/the-report/

IDS (2015a) Towards Systemic Approaches to Evaluation and Impact, IDS Bulletin 46.1

IDS (2015b) 'China's Development Finance: Ambition, Impact and Transparency', Policy Briefing, Brighton

IDS (2014) Rethinking Impact Evaluation for Development, IDS Bulletin 45.6

International Aid Transparency Initiative (IATI) www.aidtransparency.net/about accessed on 18.8.2015

IMF (2014) Factsheet: The Joint World Bank-IMF Debt Sustainability Framework for LowIncome Countries, www.imf.org/external/np/exr/facts/jdsf.htm

Kaplan, S (2014) 'Identifying Truly Fragile States’, The Washington Quarterly 37.1: 49-63

Kaplan, S. (2013) What the World Bank Does Not Understand About 'Doing Business', Policy Innovations Commentary, www.policyinnovations.org/ideas/commentary/data/000261

Kaplan, S. (2008) Fixing Fragile States: A New Paradigm for Development, Abc-clio, https://books.google.co.uk/books?hl=en\&lr=\&id=REjGWC$11 \mathrm{v} 4 \mathrm{C} \&$ oi=fnd\&pg =PR7\&dq=seth+kaplan+fragile+Fixing +Fragile+States:+A+New+Para digm+for+Development\&ots=R_Y_fPQL4w\&sig=_Zt14D-i1y5Ad1 x5A2cU1eCl9lo

Kay, J. (2012) The Kay Review of UK Equity Markets and Long-Term Decision Making, www.gov.uk/government/uploads/system/uploads/attachment_data/file/253454/bis-12917-kay-review-of-equity-markets-final-report.pdf 
Klein, P.G.; Mahoney, J.T.; McGahan, A.M. and Pitelis, C.N. (2010) 'Toward a Theory of Public Entrepreneurship', European Management Review 7.1: 1-15

Mazzucato, M. (2013) The Entrepreneurial State: Debunking Public vs Private Sector Myths, New York: Anthem Press,

http://books.google.co.uk/books?hl=en\&lr=\&id=QKd5cDPY_i4C\&oi=fnd\&pg=PR13\&dq $=$ The+Entrepreneurial+State:+Debunking + Public+vs+Private+Sector+Myths\&ots $=B k X$ wr3aEWR\&sig=Np_JAs3QS4DDz0ZOqS5Bq2z7-el

Miller, M. (2012) Climate Public Expenditure and Instittional Reviews (CPEIRs) in the AsiaPacific Region: What Have We Learnt?, UNDP

Ncube, M. and Lufumpa, C.L. (2014) Emerging Middle Class in Africa, London: Taylor and Francis

OECD (2015) Note on Rules, Methods and Classifications Used to Compile DAC Statistics, www.oecd.org/dac/stats/methodology.htm Accessed 18.8.2015

OECD (2015) Social Impact Investment: Building the Evidence Base, Paris: OECD

OECD (2014) Fragile States 2014: Domestic Revenue Mobilisation in Fragile States

OECD (2013) Role of Banks, Equity Markets and Institutional Investors in Long-Term

Financing for Growth and Development, www.oecd.org/daf/fin/private-

pensions/G20reportLTFinancingForGrowthRussianPresidency2013.pdf

Page, J. (2012) A New Agenda for Aid to Africa, The Brookings Institution

Patton, M.Q. (2011) Developmental Evaluation: Applying Complexity Concepts to Enhance Innovation and Use, New York: The Guildford Press

Sheng, A. (2013) Outlook for Global Development Finance - Excess or Shortage?, High Level Panel on the Post-2015 Development Agenda Background Research Paper

Social Impact Investment Taskforce (2014) Impact Investment: The Invisible Heart of Markets Harnessing the Power of Entrepreneurship, Innovation and Capital for Public Good

UN (2015a) Outcome Document of the Third International Conference on Financing for Development: Addis Ababa Action Agenda, 15 July 2015, accessed at https://sustainabledevelopment.un.org/post2015/transformingourworld on 18.8.2015

UN (2015b) Transforming Our World: The 2030 Agenda for Global Action, accessed at https://sustainabledevelopment.un.org/post2015/transformingourworld on 18.8.2015

UNFCCCa (2015) Scenario Note by the Co-Chairs: A Non-Paper Illustrating Possible Elements of the Paris Package, 24 July 2015, accessed at http://unfccc.int/resource/docs/2015/adp2/eng/4infnot.pdf on 18.8.2015

UNFCCCb (2015) Intended Nationally Determined Contributions, accessed at http://unfccc.int/focus/indc_portal/items/8766.php on 18.8.2015

Urpelainen, J. (2013) 'A Model of Dynamic Climate Governance: Dream Big, Win Small', International Environmental Agreements: Politics, Law and Economics 13.2: 107-25, doi:10.1007/s10784-012-9174-1 
Xu, J. (2015) 'China's Rise as Development Financer: Exploring Its Implications for International Development Cooperation', in (ed) Scott Kennedy, China and Global Governance: The Dragon's Learning Curve, Routledge

$\mathrm{Xu}, \mathrm{J}$. (2013) 'Beyond Business as Usual: Turning Challenges into Opportunities in Post2015 Development Financing Strategies', Global Policy Journal (op-ed), www.globalpolicyjournal.com/blog/25/09/2013/gg2022-\%E2\%80\%93-beyond-businessusual-turning-challenges-opportunities-post-2015-developmen

Xu, J. and Carey, R. (2015) 'The Renaissance of Public Entrepreneurship: Governing Development Finance in a Transforming Post-2015 World', Journal of International Development 27: 856-80 published online in at wileyonlinelibrary.com) DOI: 10.1002/JID.3120

Xu, J., and Carey, R. (2014) 'China's Development Finance: What Issues for Reporting and Monitoring Systems?', IDS Bulletin 45.4: 102-13

Xu, J. and Carey, R. (2013) The Renaissance of Public Entrepreneurship: Governing Development Finance in a Transforming World, Background Research Paper for the High Level Panel on the Post-2015 Development Agenda, www.post2015hlp.org/wpcontent/uploads/2013/05/Xu-Carey_The-enaissance-of-Public-EntrepreneurshipGoverning-Development-Finance-in-a-Transforming-World_FINALFINAL.pdf 